\title{
Sociodemographic Factors Related to Lower Urinary Tract Symptoms in Men: A Korean Community Health Survey
}

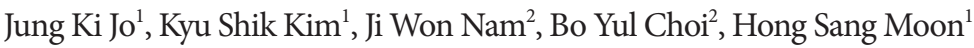 \\ ${ }^{1}$ Department of Urology, Hanyang University College of Medicine, Seoul, Korea \\ ${ }^{2}$ Department of Preventive Medicine, Hanyang University College of Medicine, Seoul, Korea
}

\begin{abstract}
Purpose: This study estimated the prevalence of lower urinary tract symptoms (LUTS) in Korean men and the conditions for being diagnosed with or treated for LUTS/benign prostatic hyperplasia (BPH).

Methods: We analyzed cross-sectional data collected from 69,851 Korean men who were 40 years of age or older and had participated in the Korean Community Health Survey performed in 2011. Interviewers performed face-to-face surveys that included sociodemographic questions, the International Prostate Symptom Score (IPSS), and questions regarding whether the subjects had been diagnosed with or treated for LUTS/BPH. We estimated the prevalence of LUTS and assessed whether the subjects had been diagnosed with or treated for LUTS/BPH.

Results: Moderate to severe LUTS, storage symptoms, and voiding symptoms increased with age. The IPSS quality of life score was $1.5 \pm 0.004$ in the mild LUTS group $(n=57,701), 3.3 \pm 0.01$ in the moderate LUTS group $(n=9,203)$, and $4.3 \pm 0.02$ in the severe LUTS group $(\mathrm{n}=2,947)(\mathrm{P}<0.0001)$. The prevalence of moderate to severe LUTS in those who had not been diagnosed with LUTS/BPH was $64.5 \%(7,847$ of 12,150), and the prevalence of moderate to severe LUTS in those who had been diagnosed with LUTS/BPH but had not been treated was $23.5 \%$ (2,853 of 12,150).

Conclusions: The severity of LUTS in Korean men increased with age, and the IPSS quality of life score increased with the severity of LUTS. Many Korean men with moderate to severe LUTS had not been diagnosed or treated for LUTS/BPH. Socioeconomic conditions played an important role in health-seeking behavior among patients with LUTS/BPH.
\end{abstract}

Keywords: Lower Urinary Tract Symptoms; Health Surveys

- Research Ethics: This study was approved by the Institutional Review Board of Hanyang University Guri Hospital (approval number: 2011-05CON-04-C).

- Conflict of Interest: No potential conflict of interest relevant to this article was reported.

\section{INTRODUCTION}

Lower urinary tract symptoms (LUTS) are common among men and affect more than half of the male population. Consequently, billions of dollars are spent annually to control and treat these symptoms $[1,2]$. While the prevalence of moderate to severe LUTS varies according to the population and age group, roughly $20 \%$ of all patients with LUTS report moderate to severe symptoms, including voiding and storage symptoms that can impact quality of life (QoL). Furthermore, LUTS has commonly been associated with a variety of other health conditions [3-7] and has been considered to be a risk factor for benign prostatic hyperplasia $(\mathrm{BPH})$ progression, along with age, low maximum urinary flow rate, and high postvoid residual

Corresponding author: Hong Sang Moon (iD https://orcid.org/0000-0003-2101-1019 Department of Urology, Hanyang University Guri Hospital, 153 Gyeongchun-ro, Guri 11923, Korea

E-mail: moonuro@hanyang.ac.kr / Tel: +82-31-560-2374 / Fax: +82-31-560-2372

Submitted: November 29, 2016 / Accepted after revision: March 31, 2017 
urine volume [8,9]. However, in epidemiologic studies, the incidence and prevalence of LUTS have been found to vary due to the differing definitions of LUTS and the associated risk factors in patient-reported results. Although men may have LUTS, they may not seek or find medical care for treatment. In a survey conducted in the United Kingdom (UK) to assess the prevalence of LUTS, only $41 \%$ of men with moderate to severe LUTS were found to exhibit health-seeking behavior, and only $18 \%$ of men had been diagnosed with BPH [10].

In the Boston Area Community Health Survey, the prevalence of moderate to severe LUTS was reported as 19.3\% [4]. The authors of the study also suggested that metabolic syndrome was associated with the severity of LUTS. In other epidemiologic surveys, the prostatic volume was found to be strongly associated with symptom aggravation and was found to increase the risk of urinary retention, which can lead to treatment and surgery for BPH $[11,12]$.

Several clinical guidelines have suggested optimal criteria for managing patients with LUTS/BPH [13-15]. However, treatment differs according to ethnic characteristics and, thus, these guidelines cannot be applied broadly. Asian men generally have lower prostatic volumes and relatively lower serum prostatespecific antigen levels than Western men, but a similar incidence of LUTS has been observed in both populations [16,17].

The aim of this study was to estimate the prevalence of LUTS in the Korean population and to investigate whether those with symptoms had been diagnosed with or treated for LUTS/BPH.
We conducted a nationwide survey to achieve this aim and to make progress towards defining practical clinical objectives for patients with LUTS/BPH.

\section{MATERIALS AND METHODS}

\section{Study Group}

This study was approved by the Institutional Review Board of Hanyang University Guri Hospital (approval number: 201105CON-04-C). Data were collected from August 2011 to October 2011 through the Korean Community Health Survey (KCHS), a nationwide health interview survey conducted in Korea by the Korea Centers for Disease Control and Prevention in order to estimate patterns of disease prevalence and morbidity among Korean adults. The target population included all Korean residents $\geq 19$ years old in the area at the time of the survey. However, because it was not possible to interview all residents $\geq 19$ years old, the survey population was based on registered residents only. Tong Ban/Lee (the smallest administrative district units) were selected as the primary sampling unit of housing types, with an average of 5 households selected per unit. The primary sampling unit was selected through probability proportionate sampling and households were systematically sampled to reduce bias. Face-to-face surveys were conducted by trained interviewers and included sociodemographic questions, the International Prostate Symptom Score (IPSS), and questions regarding whether the subjects had been diagnosed with

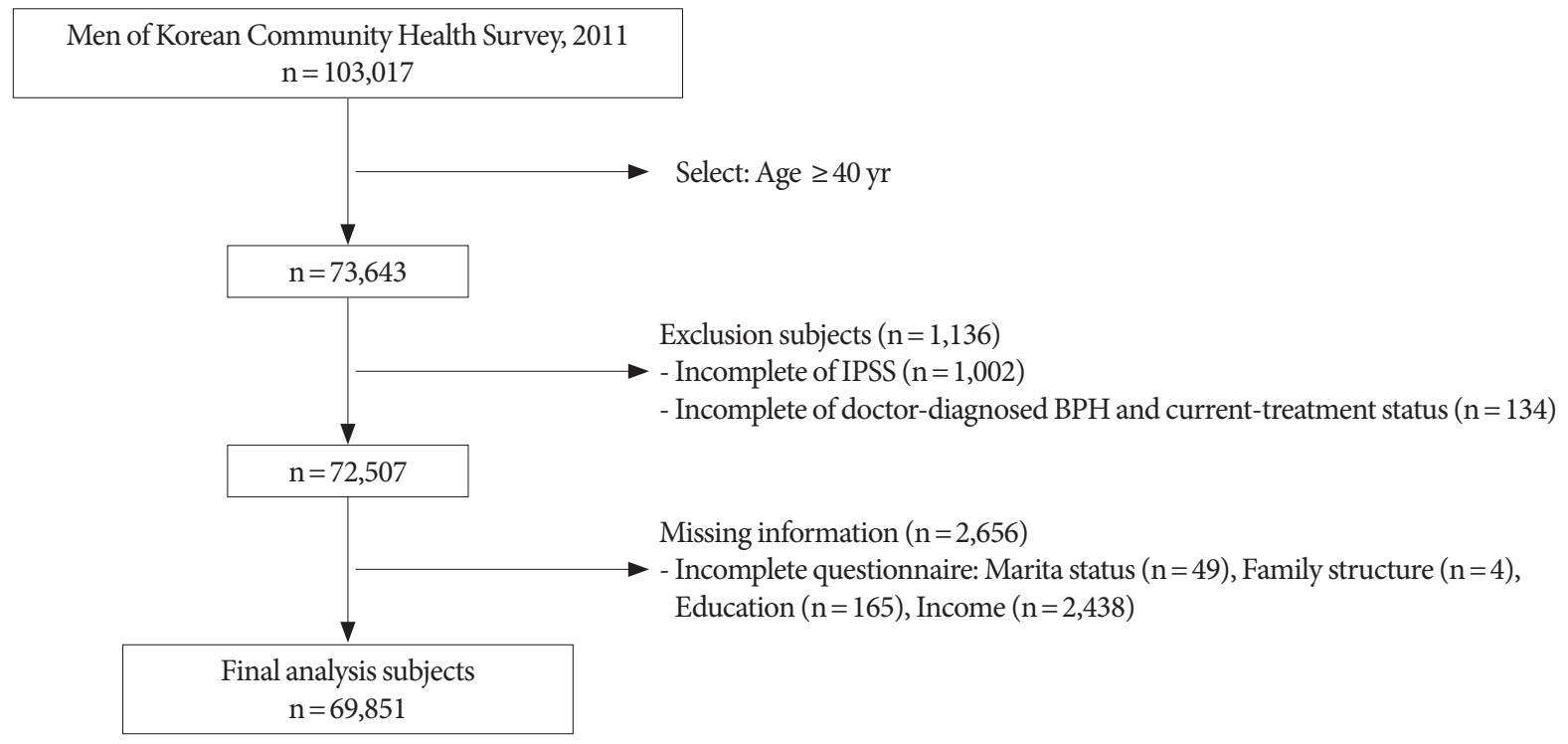

Fig. 1. Korean Community Health Survey participation flowchart. IPSS, International Prostate Symptom Score. 
or treated for LUTS/BPH.

A total of 103,017 men participated in the survey. We selected men for our analysis who were $\geq 40$ years old from this sample. We excluded subjects with incomplete questionnaires $(\mathrm{n}=1,002)$ and subjects who had uncertain medical histories regarding doctor-diagnosed $\mathrm{BPH}$ or current treatment status $(\mathrm{n}=134)$. We also excluded patients with incomplete sociodemographic information $(n=2,656)$ (Fig. 1).

We assessed age, marital status, family structure, education, income, and place of residence for the entire cohort. The severity of LUTS was stratified according to IPSS as follows: mild (IPSS $<8)$, moderate $(8 \leq$ IPSS $<20)$, and severe $(20 \leq$ IPSS $<36)$. Men without LUTS were considered to be part of the mild group. We analyzed LUTS based on storage and voiding symptoms. Doctor-diagnosed BPH and treatment status were selfreported and stratified as follows: not diagnosed, doctor-diagnosed but not currently on treatment for $\mathrm{BPH}$, and doctor-diagnosed and currently on treatment for $\mathrm{BPH}$.

\section{Statistical Analysis}

The KCHS data were subjected to a complex sampling design and were analyzed with stratum variance estimates, stratification variables, and sampling weights using the proc survey command in SAS. The IPSS scores were expressed as the mean \pm standard deviation, and distributions were shown as percentages. The prevalence of LUTS was weighted and adjusted for age by direct age standardization in order to approximate the age distribution of the national population. Prevalence estimates were based on 2005 census data that was collected by the Korea National Statistical Office

Categorical variables were analyzed with the chi-square test or Cochran-Mantel-Haenszel test and continuous variables were analyzed with a general linear model. In all analyses, the adjusted age, P-value and P for trend are presented. Statistical analyses of the associations between the severity of LUTS and sociodemographic characteristics were conducted using multivariable logistic regression models, and the weighted prevalence and age-adjusted prevalence of LUTS were stratified according to IPSS. P values less than .05 were considered statistically significant. All data were analyzed using SAS 9.4 (SAS Inc., Cary, NC, USA).

\section{RESULTS}

We collected and analyzed data from 69,851 of the 103,017 men, including those who were $\geq 40$ years old and excluding 33,166 subjects due to age, insufficient information on sociodemographic characteristics, or incomplete questionnaires. The sociodemographic characteristics at baseline for the 69,851 men are presented in Table 1.

Table 2 shows the prevalence rates of LUTS by severity according to age and $\mathrm{BPH}$. The prevalence of moderate to severe LUTS (based on both storage and voiding symptoms) was high, which correlated with increasing age (Figs. 2, 3). The IPSS-QoL score was $1.5 \pm 0.004$ in the mild LUTS group $(n=57,701), 3.3 \pm$ 0.01 in the moderate LUTS group $(\mathrm{n}=9,203)$, and $4.3 \pm 0.02$ in the severe LUTS group $(\mathrm{n}=2,947)(\mathrm{P}<0.0001)$. The prevalence

Table 1. Sociodemographic characteristics (Korean Community Health Survey, 2011) $(\mathrm{n}=69,851)$

\begin{tabular}{|c|c|}
\hline Variable & No. $(\%)$ \\
\hline \multicolumn{2}{|l|}{ Age (yr) } \\
\hline $40-49$ & $20,794(29.8)$ \\
\hline $50-59$ & $19,637(28.1)$ \\
\hline $60-69$ & $15,533(22.2)$ \\
\hline$\geq 70$ & 13,887 (19.9) \\
\hline \multicolumn{2}{|l|}{ Marital status ${ }^{\text {a) }}$} \\
\hline With spouse & $60,153(86.1)$ \\
\hline Separated & $2,339(3.4)$ \\
\hline Divorced & $2,515(3.6)$ \\
\hline Widowed & $2,394(3.4)$ \\
\hline Never married & $2,450(3.5)$ \\
\hline \multicolumn{2}{|l|}{ Family structure } \\
\hline 1 Generation & $30,664(43.9)$ \\
\hline 2 Generation & $32,552(46.6)$ \\
\hline 3 Generation & $6,635(9.5)$ \\
\hline \multicolumn{2}{|l|}{ Education } \\
\hline College or more & $16,208(23.2)$ \\
\hline High school & $24,174(34.6)$ \\
\hline Middle school & $11,360(16.3)$ \\
\hline Elementary school & $13,457(19.3)$ \\
\hline Noneducated & $4,652(6.7)$ \\
\hline \multicolumn{2}{|l|}{ Income (KRW 10,000/mo) } \\
\hline$\geq 401$ & $13,261(19.0)$ \\
\hline $301-400$ & $6,986(10.0)$ \\
\hline $201-300$ & $12,420(17.8)$ \\
\hline $101-200$ & $14,706(21.1)$ \\
\hline$\leq 100$ & $19,689(28.2)$ \\
\hline Unknown & $2,789(4.0)$ \\
\hline \multicolumn{2}{|l|}{ Dwelling place } \\
\hline County, $<50,000$ population & $26,492(37.9)$ \\
\hline Small city, $\geq 50,000$ population & $19,773(28.3)$ \\
\hline Middle city, $\geq 500,000$ population & $6,110(8.8)$ \\
\hline Metropolitan, $\geq 1,000,000$ population & $17,476(25.0)$ \\
\hline
\end{tabular}

KRW, Korean won.

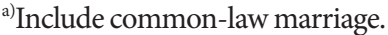


Table 2. LUTS prevalence and severity according to age and $\mathrm{BPH}$

\begin{tabular}{|c|c|c|c|c|c|c|c|c|}
\hline \multirow{3}{*}{ Variable } & \multirow{3}{*}{$\begin{array}{l}\text { IPSS score } \\
\text { Mean } \pm \text { SD }\end{array}$} & \multicolumn{6}{|c|}{ LUTS severity } & \multirow{3}{*}{ P-value $e^{\text {b) }}$} \\
\hline & & \multicolumn{2}{|c|}{$\begin{array}{l}\text { Mild }(8<\text { IPSS }) \\
\quad(\mathrm{n}=57,701)\end{array}$} & \multicolumn{2}{|c|}{$\begin{array}{c}\text { Moderate }(8 \leq \text { IPSS }<20) \\
\qquad(n=9,203)\end{array}$} & \multicolumn{2}{|c|}{$\begin{array}{c}\text { Severe }(20 \leq \text { IPSS }<36) \\
(n=2,947)\end{array}$} & \\
\hline & & No. $(\%)^{\mathrm{a})}$ & SE & No. $(\%)^{a)}$ & SE & No. $(\%)^{a)}$ & SE & \\
\hline Total (men) & $3.9 \pm 6.34$ & $57,701(86.9)$ & 0.20 & $9,203(10.3)$ & 0.10 & $2,947(2.8)$ & 0.10 & \\
\hline \multicolumn{9}{|l|}{ Age (yr) } \\
\hline $\begin{array}{l}40-49 \\
50-59 \\
60-69 \\
\geq 70\end{array}$ & $\begin{array}{l}1.3 \pm 2.86 \\
2.4 \pm 4.23 \\
4.9 \pm 6.51 \\
8.9 \pm 8.76\end{array}$ & $\begin{array}{r}20,081(96.6) \\
17,915(91.3) \\
11,997(77.2) \\
7,708(55.5)\end{array}$ & $\begin{array}{l}0.17 \\
0.28 \\
0.50 \\
0.63\end{array}$ & $\begin{array}{c}628(3.0) \\
1,463(7.5) \\
2,801(18.0) \\
4,311(31.0)\end{array}$ & $\begin{array}{l}0.17 \\
0.26 \\
0.45 \\
0.59\end{array}$ & $\begin{array}{c}85(0.4) \\
259(1.3) \\
735(4.7) \\
1,868(13.4)\end{array}$ & $\begin{array}{l}0.06 \\
0.11 \\
0.26 \\
0.44\end{array}$ & $<0.0001$ \\
\hline \multicolumn{9}{|l|}{$\begin{array}{l}\text { Self-reported doctor diagnosed } \\
\mathrm{BPH} \text { and treatment status }{ }^{\mathrm{c}}\end{array}$} \\
\hline $\begin{array}{l}\text { Nondoctor diagnosed } \mathrm{BPH} \\
(\mathrm{n}=62,090)\end{array}$ & $3.0 \pm 5.12$ & $54,243(87.4)$ & 0.20 & $6,439(10.4)$ & 0.10 & $1,408(2.3)$ & 0.10 & $<0.0001$ \\
\hline $\begin{array}{l}\text { Doctor diagnosed but noncurrent } \\
\text { treatment } \mathrm{BPH}(\mathrm{n}=4,454)\end{array}$ & $13.1 \pm 9.87$ & $1,601(35.9)$ & 2.90 & $1,709(38.4)$ & 2.80 & $1,144(25.7)$ & 2.00 & \\
\hline $\begin{array}{l}\text { Doctor diagnosed and current } \\
\text { treatment } \mathrm{BPH}(\mathrm{n}=3,307)\end{array}$ & $8.7 \pm 8.45$ & $1,857(56.2)$ & 1.30 & $1,055(31.9)$ & 1.30 & 395 (11.9) & 0.60 & \\
\hline
\end{tabular}

LUTS, lower urinary tract symptoms; BPH, benign prostate hyperplasia; IPSS, International Prostate Symptom Score; SD, standard deviation; SE, standard error.

a) The prevalence of lower urinary tract symptom (or voiding/storage symptoms) was estimated from the percentage of subjects reporting lower urinary tract symptom (or voiding/storage symptoms) after weighting for age to approximate the national population in terms of age as defined by the 2005 census performed by the Korean National Statistical Office. ${ }^{\text {b) }}$ P-values were calculated using the chi-square test and Cochran-Mantel-Haenszel test for categorical variables. ${ }^{c}$ Values were age (categorical variable: units of 10 years)-adjusted.

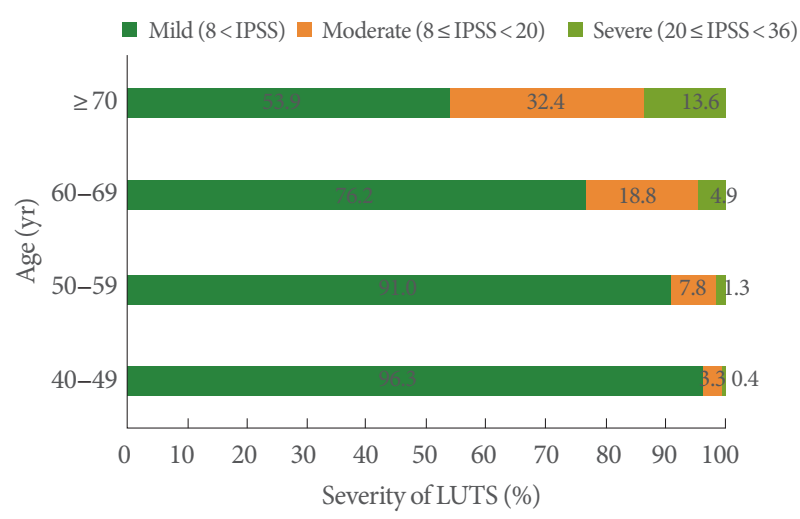

Fig. 2. Severity of lower urinary tract symptoms (LUTS) according to age group. IPSS, International Prostate Symptom Score.

of moderate to severe LUTS in those who had not been not diagnosed with LUTS/BPH was $64.5 \%$ (7,847 of 12,150), and the prevalence of moderate to severe LUTS in those who had been diagnosed with LUTS/BPH but had not been treated was $23.5 \%$ $(2,853$ of 12,150$)$.

QoL was affected by the severity of LUTS (Table 3) and was associated with both voiding and storage symptoms. We also found that the severity of LUTS was associated with sociode-

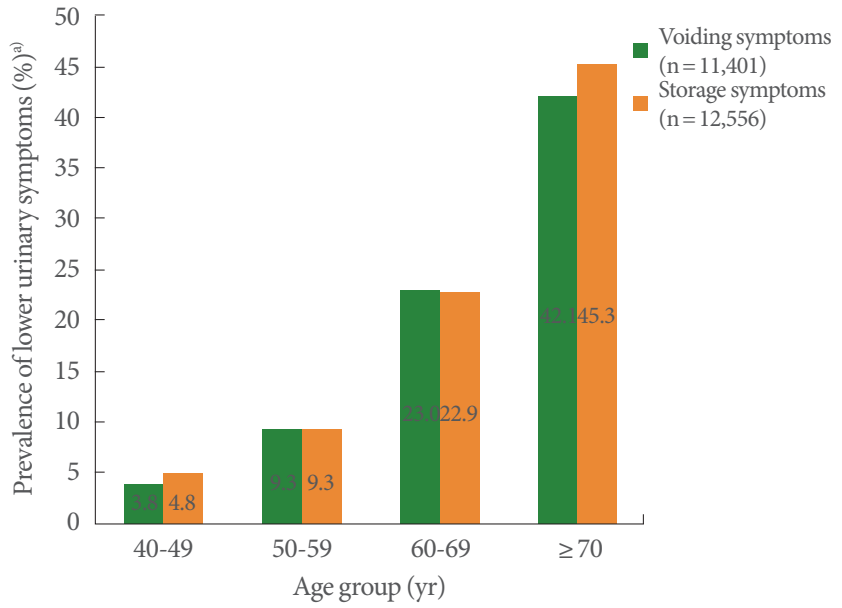

Fig. 3. Voiding and storage symptoms according to age group. a) Estimated percentage from subject reporting.

mographic characteristics (Table 4). Marital status, family structure, educational status, monthly income, and regional scales were associated with the prevalence of LUTS and with both voiding symptoms $(\mathrm{P}<0.0001, \mathrm{P}=0.1299, \mathrm{P}<0.0001, \mathrm{P}<0.0001$, $\mathrm{P}<0.0001$, respectively) and storage symptoms $(\mathrm{P}<0.0001, \mathrm{P}<$ 0.0001, $\mathrm{P}<0.0001, \mathrm{P}<0.0001, \mathrm{P}=0.0006$, respectively). 


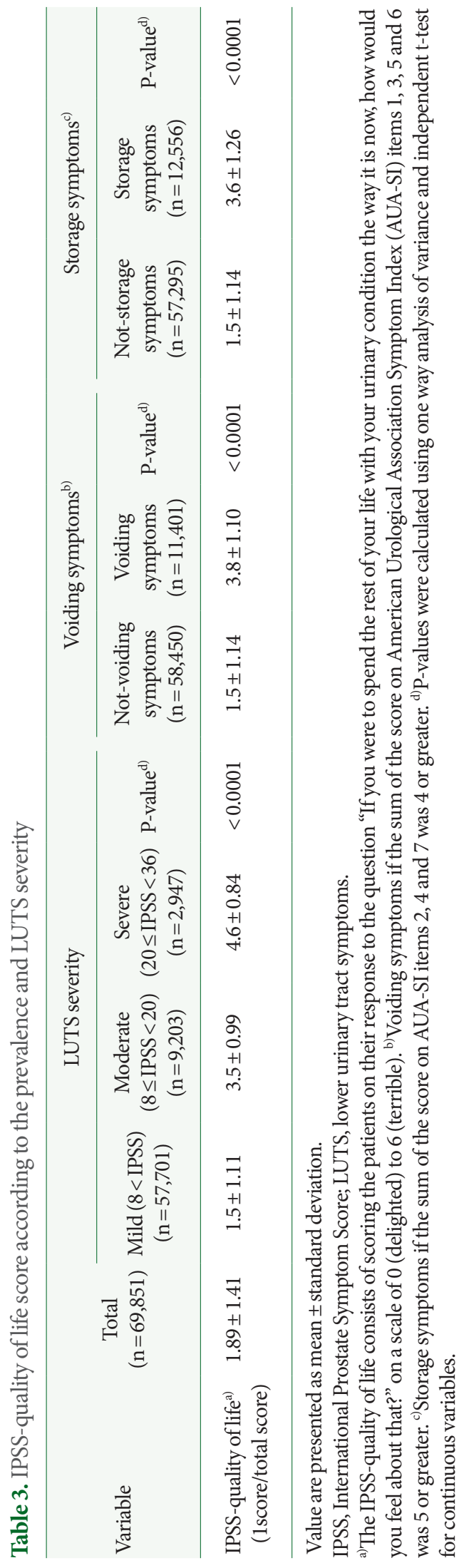

In multivariable logistic regression analysis, we found that age, marital status, family structure, educational status, income, place of residence, and QoL had a statistically significant association with the severity of LUTS (Table 5). Furthermore, we analyzed the crude model, the age-adjusted model, and the model that incorporated age adjustment, doctor-diagnosed $\mathrm{BPH}$, and treatment status. In these models, all of the aforementioned variables were found to be correlated with the severity of LUTS (all P <0.0001).

\section{DISCUSSION}

This prospective study provides insight into the prevalence of LUTS/BPH and the pattern of treatment for LUTS/BPH in Korea. Our findings expand on the results of previous epidemiologic studies for LUTS/BPH that showed that the prevalence of LUTS increased linearly with age [18-20]. Moreover, the severity of LUTS was associated with treatment patterns for LUTS/ $\mathrm{BPH}$.

This study assessed the predictors of LUTS/BPH diagnosis in the general population. Younger men with higher education levels and higher income may have had relatively easier access to care, and were, therefore, more likely to have been diagnosed with LUTS. Additionally, symptom severity and the impact on QoL increased when other socioeconomic conditions were present. Several previous surveys in Korea reported that the severity of LUTS was correlated with age $[21,22]$. In a previous study, the rate of health-seeking behavior for LUTS was also observed to increase with age in the Korean population [23]. In our survey, we found that the rate of health-seeking behavior for LUTS increased with the severity of LUTS (based on storage and voiding symptoms), and that the severity of LUTS increased with age.

Several studies have reported rates of urinary symptoms [10,23-26], and these studies have also indicated that increasing rates of LUTS correlate with increases in age. Some reports have found that men with LUTS did not seek any medical care. In our study, older men with lower education and lower income levels were more likely to have a higher severity of LUTS on diagnosis. It is possible that men that experience LUTS may perceive LUTS as a weakness and as a symptom of aging, and, thus, they may not seek help from a partner, family, or friends [27]. This may also lead to decreases in access to medical care, which could allow symptoms to progress. The results of our study indicated that lower income levels accelerated this phenomenon. 


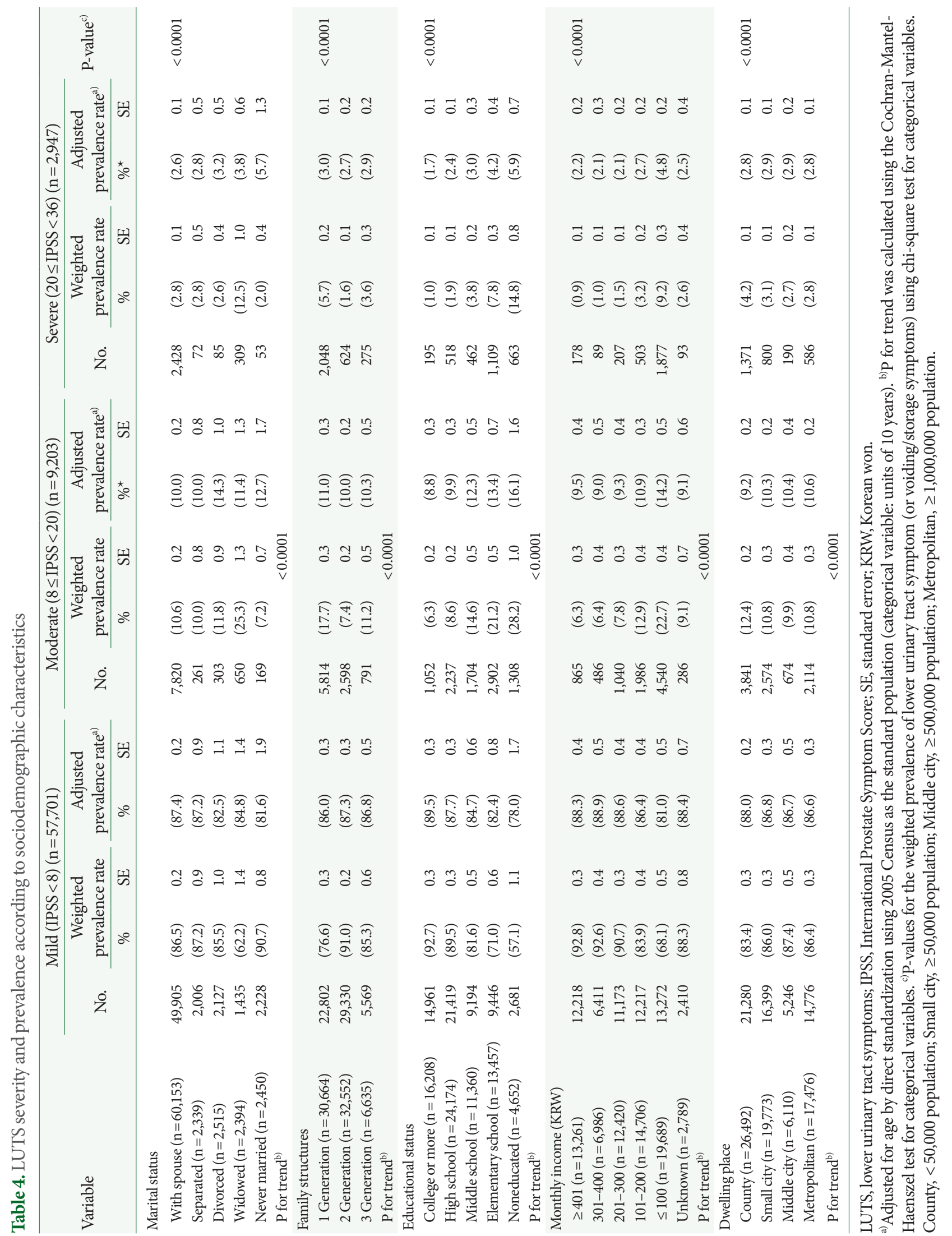


Table 5. Odds ratios (OR) and 95\% confidence intervals (CIs) from multivariable logistic regression analysis of the relationship between LUTS severity and covariates in Korean adults, 19 years or older (Korean Community Health Survey, 2011)

\begin{tabular}{|c|c|c|c|c|c|c|}
\hline \multirow{3}{*}{ Variable } & \multicolumn{6}{|c|}{ LUTS severity } \\
\hline & \multicolumn{2}{|c|}{ Crude model } & \multicolumn{2}{|c|}{ Age-adjusted model } & \multicolumn{2}{|c|}{ Adjusted model $^{\text {a) }}$} \\
\hline & OR & $(95 \% \mathrm{CI})$ & OR & $(95 \% \mathrm{CI})$ & OR & $(95 \% \mathrm{CI})$ \\
\hline \multicolumn{7}{|l|}{ Age (yr) } \\
\hline $40-49$ & 1.000 & (Reference) & & & & \\
\hline $50-59$ & 2.702 & $(2.47-2.96)$ & & & & \\
\hline $60-69$ & 8.297 & $(7.63-9.02)$ & & & & \\
\hline$\geq 70$ & 23.046 & $(21.24-25.01)$ & & & & \\
\hline P-value & $<0.0001$ & & & & & \\
\hline $\mathrm{P}$ for trend & $<0.0001$ & & & & & \\
\hline \multicolumn{7}{|l|}{ Marital status } \\
\hline With spouse & 1.000 & (Reference) & 1.000 & (Reference) & 1.000 & (Reference) \\
\hline Separated & 0.806 & $(0.72-0.91)$ & 1.017 & $(0.90-1.15)$ & 1.061 & $(0.93-1.21)$ \\
\hline Divorced & 0.886 & $(0.79-0.99)$ & 1.715 & $(1.52-1.93)$ & 1.764 & $(1.56-1.99)$ \\
\hline Widowed & 3.298 & $(3.04-3.58)$ & 1.437 & $(1.32-1.57)$ & 1.450 & $(1.33-1.59)$ \\
\hline Never married & 0.486 & $(0.42-0.56)$ & 1.799 & $(1.55-2.09)$ & 1.951 & $(1.68-2.27)$ \\
\hline P-value & $<0.0001$ & & $<0.0001$ & & $<0.0001$ & \\
\hline P for trend & $<0.0001$ & & $<0.0001$ & & $<0.0001$ & \\
\hline \multicolumn{7}{|l|}{ Family structures } \\
\hline 1 Generation & 1.000 & (Reference) & 1.000 & (Reference) & 1.000 & (Reference) \\
\hline 2 Generation & 0.317 & $(0.30-0.33)$ & 0.906 & $(0.86-0.95)$ & 0.937 & $(0.89-0.99)$ \\
\hline 3 Generation & 0.557 & $(0.52-0.60)$ & 0.992 & $(0.92-1.07)$ & 1.009 & $(0.93-1.09)$ \\
\hline P-value & $<0.0001$ & & 0.0008 & & 0.0401 & \\
\hline P for trend & $<0.0001$ & & 0.0513 & & 0.1542 & \\
\hline \multicolumn{7}{|l|}{ Education } \\
\hline College or more & 1.000 & (Reference) & 1.000 & (Reference) & 1.000 & (Reference) \\
\hline High school & 1.545 & $(1.44-1.66)$ & 1.234 & $(1.15-1.33)$ & 1.267 & $(1.17-1.37)$ \\
\hline Middle school & 2.828 & $(2.63-3.05)$ & 1.489 & $(1.38-1.61)$ & 1.610 & $(1.48-1.75)$ \\
\hline Elementary school & 5.162 & $(4.82-5.53)$ & 1.782 & $(1.65-1.92)$ & 2.035 & $(1.88-2.20)$ \\
\hline Noneducated & 9.124 & $(8.42-9.89)$ & 2.265 & $(2.07-2.48)$ & 2.792 & $(2.55-3.06)$ \\
\hline P-value & $<0.0001$ & & $<0.0001$ & & $<0.0001$ & \\
\hline P for trend & $<0.0001$ & & $<0.0001$ & & 0.000 & \\
\hline \multicolumn{7}{|l|}{ Income (KRW/mo) } \\
\hline$\geq 401$ & 1.000 & (Reference) & 1.000 & (Reference) & 1.000 & (Reference) \\
\hline $301-400$ & 1.049 & $(0.94-1.17)$ & 1.029 & $(0.92-1.15)$ & 1.081 & $(0.97-1.21)$ \\
\hline $201-300$ & 1.305 & $(1.20-1.42)$ & 1.026 & $(0.94-1.12)$ & 1.071 & $(0.98-1.18)$ \\
\hline $101-200$ & 2.383 & $(2.21-2.57)$ & 1.274 & $(1.17-1.38)$ & 1.299 & $(1.20-1.41)$ \\
\hline$\leq 100$ & 5.758 & $(5.37-6.17)$ & 1.727 & $(1.60-1.87)$ & 1.862 & $(1.72-2.02)$ \\
\hline Unknown & 1.856 & $(1.64-2.10)$ & 1.196 & $(1.05-1.37)$ & 1.241 & $(1.08-1.42)$ \\
\hline P-value & $<0.0001$ & & $<0.0001$ & & $<0.0001$ & \\
\hline P for trend & $<0.0001$ & & 0.0448 & & 0.0619 & \\
\hline \multicolumn{7}{|l|}{ Dwelling place } \\
\hline County & 1.000 & (Reference) & 1.000 & (Reference) & 1.000 & (Reference) \\
\hline Small city & 0.836 & $(0.80-0.88)$ & 1.190 & $(1.13-1.25)$ & 1.165 & $(1.11-1.23)$ \\
\hline Middle city & 0.668 & $(0.62-0.72)$ & 1.196 & $(1.10-1.30)$ & 1.103 & $(1.01-1.20)$ \\
\hline Metropolitan & 0.74 & $(0.70-0.78)$ & 1.148 & $(1.09-1.21)$ & 1.079 & $(1.02-1.14)$ \\
\hline P-value & $<0.0001$ & & $<0.0001$ & & $<0.0001$ & \\
\hline P for trend & $<0.0001$ & & 0.000 & & 0.0041 & \\
\hline IPSS-quality of life (1score/total score) & 5.063 & $(4.94-5.19)$ & 4.572 & $(4.46-4.69)$ & 4.410 & $(4.30-4.53)$ \\
\hline P for trend & $<0.0001$ & & $<0.0001$ & & $<0.0001$ & \\
\hline
\end{tabular}

LUTS, lower urinary tract symptoms; IPSS, International Prostate Symptom Score; KRW, Korean won.

a) Adjusted for age (categorical variable: units of 10 years) and doctor diagnosed benign prostate hyperplasia (BPH) and treatment status (categorical variable: nondoctor diagnosed $\mathrm{BPH}$, doctor diagnosed but noncurrent treatment $\mathrm{BPH}$, doctor diagnosed and current treatment $\mathrm{BPH}$ ). 
A previous study also reported that age was associated with similar results and reported that the symptom rate and severity of LUTS increased with age [28].

Interestingly, the severity of LUTS was found to be directly associated with the decision to consult a physician. A previous study reported the same finding and also found that age was associated with the decision to seek a physician for LUTS [10]. Furthermore, we found that the severity of LUTS was associated with several other factors, including age, education level, income level, living environment, and most importantly marital status and family structure. Marital status and family structure had an impact on access to care for LUTS and were correlated with a greater likelihood of patients neglecting their symptoms. In particular, some patients who had low income levels, were separated or divorced, or who resided within a nonmultigenerational family structure did not necessarily seek medical care, even with severe LUTS, perhaps due to the relative weakness of such family structures. This may be exacerbated by the possibility that such a family structure may be accompanied by having a lower income or being separated or divorced. On the contrary, certain urinary symptoms, such as nocturia, might lead men with LUTS to actively seek treatment. Nocturia can lead to daytime drowsiness and can impact concentration and decrease motivation, which may negatively affect the ability to perform activities [29] and lead men to seek care. However, in general, many patients ignore LUTS until it becomes so severe that they cannot continue without medical care.

There are some substantial differences in the diagnosis and treatment of LUTS among different countries. In the UK, men with LUTS were less likely to be diagnosed than those in other European countries. In Italy, men with LUTS were more likely to be diagnosed, followed by Germany, France, and Spain. Different healthcare systems may affect access to care, and cultural differences also influence the rate of access [28].

This observational study evaluated the prevalence of LUTS/ $\mathrm{BPH}$ and the pattern of treatment via a nationwide survey. However, our results should be interpreted within the context of our study's limitations. First, this study was an observational study, and we did not interfere with the treatment patterns. Second, our data did not include clinical laboratory data. Therefore, we were unable to assess objective data such as maximal flow rate and postvoid residual urine volume on uroflowmetry. Despite these limitations, this study cohort was representative of national data and we were able to evaluate the prevalence of LUTS/BPH and to assess current treatment patterns.
In conclusion, the severity of LUTS was found to increase according to age and the IPSS-QoL score among participants in our study. Furthermore, many participants with moderate to severe LUTS had not been diagnosed with or treated for LUTS/ $\mathrm{BPH}$. This lack of treatment was associated with several factors, including socioeconomic and individual health conditions.

\section{ACKNOWLEDGMENTS}

The authors appreciated all participating citizens in $2011 \mathrm{KCHS}$ and all members of the 2011 KCHS team.

\section{REFERENCES}

1. Irwin DE, Milsom I, Kopp Z, Abrams P, Artibani W, Herschorn S. Prevalence, severity, and symptom bother of lower urinary tract symptoms among men in the EPIC study: impact of overactive bladder. Eur Urol 2009;56:14-20.

2. Hu TW, Wagner TH, Bentkover JD, Leblanc K, Zhou SZ, Hunt T. Costs of urinary incontinence and overactive bladder in the United States: a comparative study. Urology 2004;63:461-5.

3. Kupelian V, Wei JT, O’Leary MP, Kusek JW, Litman HJ, Link CL, et al. Prevalence of lower urinary tract symptoms and effect on quality of life in a racially and ethnically diverse random sample: the Boston Area Community Health (BACH) Survey. Arch Intern Med 2006;166:2381-7.

4. Kupelian V, Rosen RC, Link CL, McVary KT, Aiyer LP, Mollon P, et al. Association of urological symptoms and chronic illness in men and women: contributions of symptom severity and duration--results from the BACH Survey. J Urol 2009;181:694-700.

5. Coyne KS, Kaplan SA, Chapple CR, Sexton CC, Kopp ZS, Bush EN, et al. Risk factors and comorbid conditions associated with lower urinary tract symptoms: EpiLUTS. BJU Int 2009;103 Suppl 3:24-32.

6. Coyne KS, Wein AJ, Tubaro A, Sexton CC, Thompson CL, Kopp ZS, et al. The burden of lower urinary tract symptoms: evaluating the effect of LUTS on health-related quality of life, anxiety and depression: EpiLUTS. BJU Int 2009;103 Suppl 3:4-11.

7. Malmsten UG, Molander U, Peeker R, Irwin DE, Milsom I. Urinary incontinence, overactive bladder, and other lower urinary tract symptoms: a longitudinal population-based survey in men aged 45-103 years. Eur Urol 2010;58:149-56.

8. Lowe FC, Batista J, Berges R, Chartier-Kastler E, Conti G, Desgrandchamps F, et al. Risk factors for disease progression in patients with lower urinary tract symptoms/benign prostatic hyper- 
plasia (LUTS/BPH): a systematic analysis of expert opinion. Prostate Cancer Prostatic Dis 2005;8:206-9.

9. Crawford ED, Wilson SS, McConnell JD, Slawin KM, Lieber MC, Smith JA, et al. Baseline factors as predictors of clinical progression of benign prostatic hyperplasia in men treated with placebo. J Urol 2006;175:1422-6.

10. Trueman P, Hood SC, Nayak US, Mrazek MF. Prevalence of lower urinary tract symptoms and self-reported diagnosed 'benign prostatic hyperplasia, and their effect on quality of life in a communitybased survey of men in the UK. BJU Int 1999;83:410-5.

11. Roehrborn CG, Malice M, Cook TJ, Girman CJ. Clinical predictors of spontaneous acute urinary retention in men with LUTS and clinical BPH: a comprehensive analysis of the pooled placebo groups of several large clinical trials. Urology 2001;58:210-6.

12. McConnell JD, Bruskewitz R, Walsh P, Andriole G, Lieber M, Holtgrewe HL, et al. The effect of finasteride on the risk of acute urinary retention and the need for surgical treatment among men with benign prostatic hyperplasia. Finasteride Long-Term Efficacy and Safety Study Group. N Engl J Med 1998;338:557-63.

13. McVary KT, Roehrborn CG, Avins AL, Barry MJ, Bruskewitz RC, Donnell RF, et al. Update on AUA guideline on the management of benign prostatic hyperplasia. J Urol 2011;185:1793-803.

14. Madersbacher S, Alivizatos G, Nordling J, Sanz CR, Emberton M, de la Rosette JJ. EAU 2004 guidelines on assessment, therapy and follow-up of men with lower urinary tract symptoms suggestive of benign prostatic obstruction (BPH guidelines). Eur Urol 2004;46: 547-54.

15. Irani J, Brown C, Van der Meulen J, Emberton M. International comparison of guidelines for the management of benign prostatic hyperplasia: use of a validated generic tool. Prog Urol 2004;14:2932.

16. Chung BH, Hong SJ, Cho JS, Seong DH. Relationship between serum prostate-specific antigen and prostate volume in Korean men with benign prostatic hyperplasia: a multicentre study. BJU Int 2006;97:742-6.

17. Lee E, Yoo KY, Kim Y, Shin Y, Lee C. Prevalence of lower urinary tract symptoms in Korean men in a community-based study. Eur Urol 1998;33:17-21.

18. Irwin DE, Milsom I, Hunskaar S, Reilly K, Kopp Z, Herschorn S, et al. Population-based survey of urinary incontinence, overactive bladder, and other lower urinary tract symptoms in five countries: results of the EPIC study. Eur Urol 2006;50:1306-14.
19. Engström G, Walker-Engström ML, Lööf L, Leppert J. Prevalence of three lower urinary tract symptoms in men-a population-based study. Fam Pract 2003;20:7-10.

20. Rosen R, Altwein J, Boyle P, Kirby RS, Lukacs B, Meuleman E, et al. Lower urinary tract symptoms and male sexual dysfunction: the multinational survey of the aging male (MSAM-7). Eur Urol 2003; 44:637-49.

21. Jeong WS, Choi HY, Nam JW, Kim SA, Choi BY, Moon HS, et al. Men with severe lower urinary tract symptoms are at increased risk of depression. Int Neurourol J 2015;19:286-92.

22. Kim TH, Han DH, Lee KS. The prevalence of lower urinary tract symptoms in korean men aged 40 years or older: a populationbased survey. Int Neurourol J 2014;18:126-32.

23. Kwon CS, Lee JH. Prevalence, risk factors, quality of life, and health-care seeking behaviors of female urinary incontinence: results from the 4th Korean National Health and Nutrition Examination Survey VI (2007-2009). Int Neurourol J 2014;18:31-6.

24. Seftel AD, de la Rosette J, Birt J, Porter V, Zarotsky V, Viktrup L. Coexisting lower urinary tract symptoms and erectile dysfunction: a systematic review of epidemiological data. Int J Clin Pract 2013; 67:32-45.

25. Braun MH, Sommer F, Haupt G, Mathers MJ, Reifenrath B, Engelmann UH. Lower urinary tract symptoms and erectile dysfunction: co-morbidity or typical "Aging Male" symptoms? Results of the "Cologne Male Survey". Eur Urol 2003;44:588-94.

26. Boyle P, Robertson C, Mazzetta C, Keech M, Hobbs FD, Fourcade $\mathrm{R}$, et al. The prevalence of lower urinary tract symptoms in men and women in four centres. The UrEpik study. BJU Int 2003;92: 409-14.

27. Wong SY, Woo J, Leung JC, Leung PC. Depressive symptoms and lifestyle factors as risk factors of lower urinary tract symptoms in Southern Chinese men: a prospective study. Aging Male 2010;13: 113-9.

28. Foster SA, Shortridge EF, DiBonaventura M, Viktrup L. Predictors of self-reported benign prostatic hyperplasia in European men: analysis of the European National Health and Wellness Survey. World J Urol 2015;33:639-47.

29. Breyer BN, Kenfield SA, Blaschko SD, Erickson BA. The association of lower urinary tract symptoms, depression and suicidal ideation: data from the 2005-2006 and 2007-2008 National Health and Nutrition Examination Survey. J Urol 2014;191:1333-9. 